\title{
THE MEDICAL SERVICE OF THE ARMY.
}

\section{PROPOSITIONS AND SUGGESTIONS.}

THE following suggestions are intended to proceed from the starting point of certain facts which no one is likely to gainsay.

It is intended, in the course of them, to avoid the expression of any opinion, one way or another, on what may be called subjects of current controversy, and to refer to these only in so far as they may indicate data which are not open to dispute.

The Propositions are,-

1. That there exists, rightly or wrongly, profound discontent and inquietude among the medical officers of the army.

2 . That the profession at large thoroughly sympathizes with these feelings, and that the sympathy so felt has penetrated to all classes, from the President of the General Council to the youngest student.

3. That these feelings, in great measure, owe their origin to assaults, real or imaginary, on amour propre, or that just, virtuous, manly form of pride, which may be called professional ésprit; also, that they stand in the relation of cause and effect to the ugly words " broken faith," whether these words are used rightly or wrongly.

4. That discontent, so caused, is always deep in its effects, and lasting in its results.

5. That the profession, as offering its services to the public for a money value, is in a position to make for itself better terms now than was the case, say, twerty years ago.

6. That preliminary education, more elaborate and higher instruction, Ideferred age for graduation, the many new openings for profitable employment of one's life and energy which are yearly offered to the middle classes, and many other cognate considerations, make it reasonable to predict that the profession will, year by year, be able to demand better and still better terms.

7. That on the outbreak of war, the present supply of officers would be found quite inadequate, and that even the offer of very high terms would then fail to procure a sufficient supply:

8. That, in effect, the supply of candidates is now insufficient, and the quality indifferent.

9. That the prospect of promotion for assistant-surgeons is now a very bad one, which is daily becoming worse, and that for surgeons there is next to no prospect of promotion whatever.

10. That the purchasing power of any given rate of full or halfpay is now less than it was, say, twenty years ago, and that the demands on any given rate of full pay are now greater than they were twenty years ago.

11. That it is most desirable, in the public service, as in all 
other businesses of life, while satisfying all just claims, to combine the strictest economy with the highest efficiency.

12. That the system of so-called medical administration in the army is very costly, while its usefulness is, at least, open to doubt; that it is quite unknown to the profession elsewhere, and is essentially opposed to all professional instincts and tendencies; while, speaking militarily, it is altogether divergent from the fundamental principles of discipline and good order.

One more proposition before going further.-

The true conception of the position of a medical officer, as regards his duties, is this, -

1. He has to treat sick; that is, to take a man into hospital when he is sick, treat him there, and discharge him when he is whole.

2. He is required, on occasion, to declare principles of sanitation, and to make recommendations and suggestions in that sense.

Beyond these he has no functions whatever.

\section{SUGGESTIONS.}

I.-Abolish the Medical Department.

II.-Diligently search for the ablest, wisest, shrewdest, sensiblest man in the medical service, a man of experience, who has been instructed by experience, and place him in the War Office as the adviser on all health-questions of the Secretary for War. Let all statements, returns, and letters relating to the health, and healthconditions of the army pass to that officer through the hands of respective commanding officers. Then, on all these matters, the so-constituted adviser would take action, speaking in the name of the Secretary for War.

It may surprise some people to be told that a commanding officer of a regiment ought to be acquainted with all reports relating to his command; that, in one word, he ought to command it; but, in fact, it would be just as reasonable to say that one man should command at the stern of a ship and another at the forward part, as to say that a commanding officer should command one part of his regiment and that a surgeon or a principal medical officer should command another part. $\mathrm{It}$ is quite contrary to the very first principles of discipline that any report relating to a regiment or other command should be, in the first instance, addressed to any person whatever other than the commanding officer.

For regulating the medical affairs of the army, the old Medical Boards lamentably and avowedly proved utter failures. It is not too much to assert that the more modern system of a so-called Director-General - we are speaking of a system, not of personshas failed as signally. It can imply no disparagement of the able and laborious officers who have successfully filled the office to say 
that it would be surprising if it were otherwise. Selected on the ground of distinguished ability in the discharge of quite other functions, these men are expected to perform prodigies with powers quite incommensurate. In fact, the very name and title of DirectorGeneral involves an assurance and a prediction of failure. It implies an amount of power which does not, and, in the nature of things, cannot exist. To some eight hundred officers of his own department he is a supreme being, expected to satisfy every individual wish, with little power to do one thing or another, and to maintain, on all points, the requirements of professional dignity, in the presence of all opposition. To about the same number of war-office clerks, he is "only a doctor," and, therefore, a ready target for their sharp, obstructive pens. Our sanitary adviser, on the other hand, would, on all subjects within his province and to all men, speak in the name of the Secretary for War, all responsibility resting on that high officer. Instead of the medical section being in an attitude of seeming quasi-independence and possible antagonism it would be in harmonious subordination to and unification with the central authority. Thus, by surrendering an elevation of rank which is more apparent than real, there would be a gain of directing power and an immense simplification of routine.

An officer similarly selected, and with like functions, would be attached to the staff of any army in the field.

As for India, the detail of these duties has been provided for by the recent commission.

III.-Place the direction of all matters relating to the appointing, transferring, promoting, and all other movements of medical officers, as are the movements of other officers, in charge of the AdjutantGeneral.

IV.-Publish a code of sanitary regulations, having the force of the general orders and regulations of the army, and adapted to the army as it is.

It is characteristic of the way in which the War Office takes care of the public money, that the most marked result of the outbreak of feeling on sanitary questions a few years ago was an extension of the costly and cumbersome system of administration, and that an elaborate scheme for reporting, inspecting, advising, and, in one word, circumlocutionizing, on these points, was laid down, while the sanitary rules and regulations were of the most meagre and perfunctory character.

It is odd, under the circumstances, that this extension and, so to speak, authentication of the administrative system should have been effected in such a way as to seem as if it was the immediate consequence of the severe condemnation of it which had just been recorded by such authorities as Lord Herbert, Miss Nightingale, and the Scutari Commissioners. But so it was. It would hardly be possible to use stronger language than that in which this system was condemned by these persons. 
When we think of the miles of weary and purposeless perambulation, the yards of quite ineffective reports, and the amount of personal vexation and inter-departmental jealousies and misunderstandings that would have been saved by the simple expedient of publishing a code of regulations six years ago, one may safely assert that the grand problem of "how not to do it" has, in this instance, been more than achieved.

In one word, a code of regulations would be an immense boon to all parties. The promulgation of it would be a long step towards simplification, and it would remove one excuse which may be urged for the maintenance of the present system of administration.

V.-There is no occasion for medical officers to wear a uniform, nor need they be members of messes.

Most of the unhappinesses of which we have heard lately seem to be connected with these two matters.

There is really no intelligible reason why a surgeon should be dressed in uniform, and there are isome reasons why he should not. In the field, before an enemy, it would be very easy, if deemed necessary, to discover some means of distinguishing him without offending himself or any other people. Already, by a recent order, a certain section of medical officers has been excepted from the necessity of wearing uniform, and there does not appear to be any valid reason why the boon should not be extended to the permanent officers which has been bestowed on their " more favoured brethren" of the acting staff.

The exemption from compulsory mess-membership would be a benefit to all parties. When the other members do not wish a medical officer to join them, it would be strange if he wished to force himself into their social gathering. If they wished his company, it would be still practicable for them to seek it. Further, the members would be relieved from the pain of a possible conflict between, on the one hand, prejudices which are perhaps not very unnatural, and on the other, their respect for the Queen's authority on the unhappy question of precedence, while the medical officer would be saved from the possible most unpleasant duty of insisting on the Queen's authority on that point being attended to.

VI. - Establish a rate of optional half-pay, to commence at a low rate, at say, ten years, to increase gradually until it culminates in 18s. 6d. at twenty years' service, with permission, at all periods, to return to full pay until the age of fifty-five is attained. ${ }^{1}$

It would be a pity to increase the present full-pay rates. The jealousy that would be excited by any such increase would not be counterbalanced by any possible degree of improvement of the rate.

For a young surgeon looking out for a career there are two in-

1 At present there is a half-pay rate of $16 \mathrm{~s}$. $6 \mathrm{~d}$. after twenty years, but that is only procurable on evidence of bad health, and the officer is brought back for five years' more full-pay service as soon as his health is re-established. 
ducements which may possibly determine him to seek the army medical service. These are, in a slight degree, the red coat; in a greater degree, the notion that he may be able to make both ends meet on $£ 182,10$ s. After a very brief acquaintance, the first loses its attraction, and he is very apt to find that he has made a mistake about the second. Very few enter with the intention of making it their life-business. They think that they can spend, in the army, profitably and agreeably, the few years which must intervene before they can be held qualified for good practice. When the time comes, however, at which they had thought of leaving, they are abroad, or they have no money to start with, or other considerations intervene, and they hold on till a more convenient season. They see their military comrades, with whose prospects they cannot help, erroneously perhaps, comparing their own, looking for progress and promotion, gaining promotion, making progress, in fact, in many ways. For themselves, they see no such prospect. Then, year by year, quite imperceptibly, time flows on till they begin to think that it would be foolish to sacritice so long service for no return. At length, they approach the stage when they sedulously fix their eyes on the twenty-five years' retirement, count the days till that period is to be reached, look on the "style of surgeon-major" as a pleasant mile-stone on a weary road, and, sighing for liberty, they remain in what they foolishly call bondage until the fugacious years have all glided past, and they think, too late, alas! that their life,-the working, healthy, vigorous days of it, at least, - has been thrown away.

The Commission which sat in 1857 was urged to recommend an optional retirement, at a low rate, at twenty years. This would be a boon to the exceedingly small number of officers who possess private means; but their number is so small that the granting of it would not appreciably affect promotion or the general interests in any way; while, for the same reason, it would be quite safe, in the interest of the public, to concede it.

A rate of retirement, obtainable at a comparatively early period, would enable many to pass out into private life, and it may be assumed that a certain proportion of such would always be willing to return. It would diffuse much general contentment, and would tend to procure the services of a very good class. It would cause a happy interchange, which now hardly exists, between civil and military practice. It ought to be remembered, in this connexion, that famous men of whom the public services are most justly proud, as John Hunter, Sir John Pringle, Brocklesby, and Sir Gilbert Blaine, did not, in the modern sense, belong to their respective departments at all.

Eighteen shillings and sixpence after twenty years may seem a large sum, but, under existing circumstances, that being now obtainable after twenty-five years, any lower rate would have no effect whatever, except to remove the small number already referred to who

voL. X.- - No. v. 
may possess private means. $A$ man who is without any private means will hold on until he can get the largest sum procurable. Many would take advantage of the $18 \mathrm{~s}$. $6 \mathrm{~d}$., but of these a large proportion would soon grow tired of want of employment, and be anxious, after a little, to return, and they would then serve cheerfully and contentedly until the fatal period of fifty-five years of age.9 In that way, if the thing was looked at boldly, and adopted, it would not result that the Treasury suffered to nearly such an extent as might, at first sight, be anticipated, while a wholesome current of promotion would have been set in motion. It may be objected that the non-effective list might, thereby, be made to bear a disproportion to the effective list, and, on general grounds, that is an objection of moment. But the question is, whether or not there exist, in the present instance, sufficient grounds for running the risk of a possible departure from abstract rules. Again, if this good early retirement did add to expenditure, consider how very much would be saved by the extinction of the whole class of "medical administrators ;" not merely in actual or prospective pay, but in allowances, clerks, quarters, foolscap, red tape, and many other items. The mode of death selected for them would necessarily be gradual. It ought to be made easy, even luxurious.

The very large sum so saved would make it possible to grant, in addition to half-pay, a certain number of good-service pensions. This would be a great boon, and the good effect of it would be far beyond the mere value of the money expended.

This question of the condition, present and prospective, of medical matters in the army, is one of really considerable public importance. If pressing for settlement now, it will be much more urgently pressing in the event of an outbreak of war. It is just one of those questions, small as compared with many others, which require for their solution a mind incapable of being biassed by prejudice, judicial, statesmanlike. A delay can cause nothing but more embarrassment, a more plentiful crop of illusions, and a furtherinterchange of deplorable vituperation. And it behoves those who have eaten the bread of the service for years, and who have not-as indeed many can say-found it very bitter, thinking moderately, to speak dispassionately on a subject so nearly affecting the interests of their profession.

It is related that, once, when Ambrose Parè was thrown into a besieged place, the drooping spirits of the garrison were thereby raised to such a degree as to cause a stout and successful resistance. This was because they felt that they had a surgeon among them who knew his business, and who would not dress their wounds with boiling pitch, or use the actual cautery for the arrestment of hæmorrhage. It is really quite possible that, on some future critical occasion, the fate of events may turn on whether there is present a sufficient number of sound, skilful surgeons, or only a meagre 
supply of men modelled after the type of that enterprising and now famous neophyte who is prepared to take off the quarter of a man's body in case of the femoral artery being punctured.

One has only to look about him to be convinced that the arrangement inaugurated in 1858, and with regard to which such high hopes were entertained, has proved a failure. When speculating as to what plan ought to supersede it, and some radically new plan must be devised, sooner or later, it is the part of a wise man to ascertain where there has been weakness, and then, by the light of that discovery, to provide for the future. What is past ought to be held to be past and gone, and potent elements of discord and disorder ought to be avoided or thrown aside.

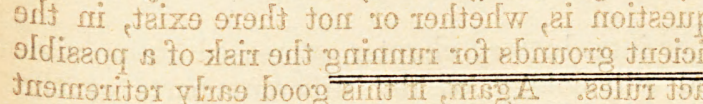

\section{วดart Ecconto.}

to 9 bom arti

of trigmo JI. Isubsig

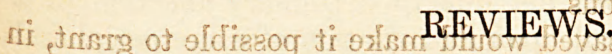

Clinical Observations on Functional Nervous Disorders. By C. H AndField Jones, M.B. Cantab.; F.R.C.P. Lond.; Physician to St Mary's Hospital. London: Churchills: 1864.

No class of diseases is of greater interest to the physician than those affecting the nervous system, and regarding none, until very lately, has so much uncertainty prevailed. Recent anatomical and physiological researches have cleared up much that was obscure, and our increased knowledge of structure and function has been gradually leading to clearer views of the morbid conditions to which the nervous system is liable. It is the object of $\mathrm{Dr}$ Jones in the work before us to consider from a clinical point of view those nervous diseases in which no manifest organic lesion can be discovered. Since pathological anatomy has been successfully cultivated it has been a constant subject for discussion, whether any disorders are to be considered as purely functional; advancing knowledge and finer methods of abseryation have been constantly diminishing the number of functional diseases, and the admirable researches of Lockhart Clarke have shown that there may be advanced disorganization of nervous structure, which is quite inappreciable to the naked eye. It is, in fact, very doubtful whether such a thing as a purely functional disease can exist; we may indeed suppose it to ibe functional in its commencement, but very speedily, possibly before any symptoms manifest themselves, an organic change takes place. Di Jones, while adopting the division of diseases into 